\title{
Schoepfia Fruit Fly, Anastrepha interrupta Stone (Insecta: Diptera: Tephritidae) ${ }^{1}$
}

H. V. Weems, Jr. and J. B. Heppner²

\section{Introduction}

The schoepfia fruit fly, Anastrepha interrupta Stone, is native to southern Florida and one of six Anastrepha species which occur in or have been established in Florida at some time. The species was described from southern Florida (Stone 1942) and is thus far known only from coastal counties of south-central Florida to Key West. The schoepfia fruit fly has not been found on any economic fruits and is only known to feed on fruit of Schoepfia chrysophylloides (A. Rich.) Planch. (Olacaceae) (Weems 1967).

While populations of interrupta fluctuate greatly in different years and at different times of the year, this is the most common of the so-called native species, and it has been taken by traps in every month of the year. Only the Caribbean fruit fly, Anastrepha suspensa (Loew), believed to be a recent re-introduction into Florida, is more abundant and widespread in Florida.

\section{Distribution}

Southern Florida (counties: Martin, St. Lucie, Brevard, Palm Beach, Broward, Collier, Lee, Dade, and Monroe, including Key West). The type locality is Jensen, Florida.

\section{Life History}

The life history of Anastrepha interrupta has not been ascertained, although adults have been reared several times from the fruit of Schoepfia chrysophylloides, a plant indigenous to southern Florida.

\section{Identification}

Small yellowish fruit fly, approximately the size of a house fly, with rather long, patterned wings. Except for A. suspensa, A. interrupta may be distinguished readily from other members of the genus which occur in Florida by the presence of a black scutoscutellar spot.

1. This document is EENY-267 (originally published as DPI Entomology Circulars 61 and 327), one of a series of Featured Creatures from the Entomology and Nematology Department, Florida Cooperative Extension Service, Institute of Food and Agricultural Sciences, University of Florida. Published: January 2002. This document is also available on Featured Creatures Website at http://creatures.ifas.ufl.edu. Please visit the EDIS Website at http://edis.ifas.ufl.edu. Additional information on these organisms, including many color photographs, is available at the Entomology and Nematology Department website at http://entnemdept.ifas.ufl.edu/.

2. H.V. Weems and J.B. Heppner, Florida Department of Agriculture and Consumer Services, Division of Plant Industry, Gainesville, FL.

The Institute of Food and Agricultural Sciences (IFAS) is an Equal Employment Opportunity - Affirmative Action Employer authorized to provide research, educational information and other services only to individuals and institutions that function without regard to race, creed, color, religion, age, disability, sex, sexual orientation, marital status, national origin, political opinions or affiliations. For information on obtaining other extension publications, contact your county Cooperative Extension Service office. Florida Cooperative Extension Service / Institute of Food and Agricultural Sciences / University of Florida / Larry R. Arrington, Interim Dean 


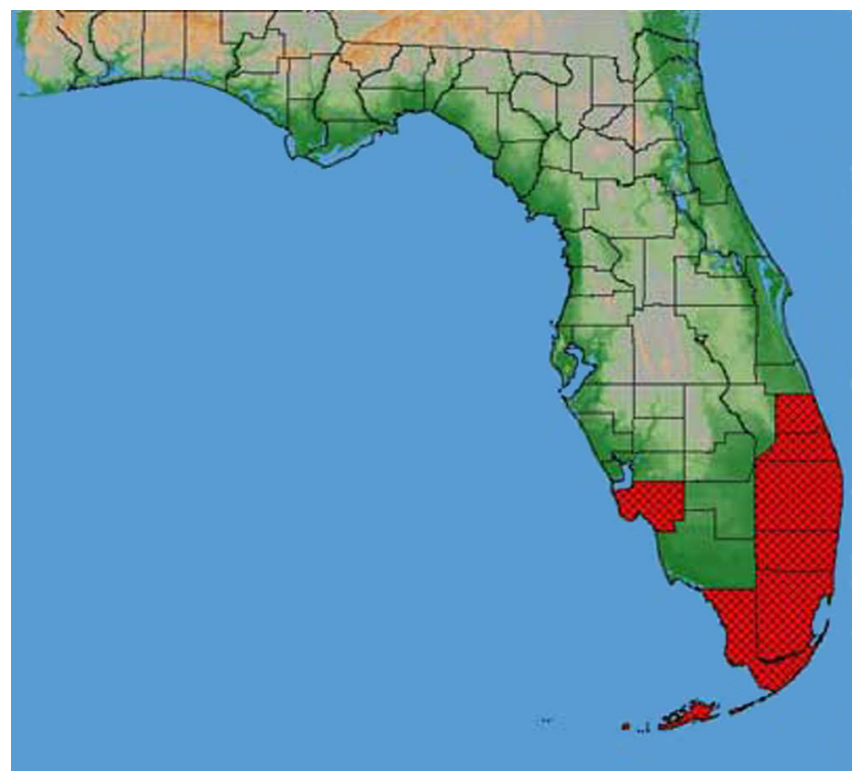

Figure 1. Distribution in Florida of the schoepfia fruit fly, Anastrepha interrupta Stone. Credits: G.J. Steck and B.D. Sutton, Division of Plant Industry

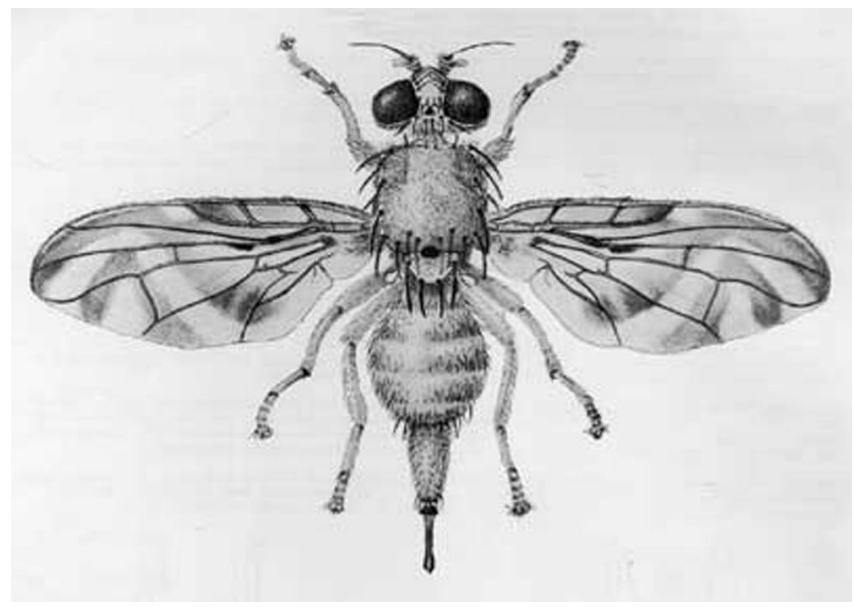

Figure 2. Adult female schoepfia fruit fly, Anastrepha interrupta Stone. Credits: Division of Plant Industry

It may be distinguished from suspensa by the shape of the ovipositor of the female. The tip of the ovipositor of interrupta is short and broad, with many fine serrations, whereas that of suspensa is long and tapering, with larger, rounded serrations occupying the apical two-thirds of the tip.

The thoracic spines of interrupta are yellowish brown, while those of suspensa are dark brown to black. The wing patterns of the two species, while similar, show characteristic difference. The wing pattern of interrupta is mostly yellowish with much less infuscation than that of suspensa, and the $\mathrm{V}$ band is not connected at its apex with the bands on the anterior portion of the wing, whereas in suspensa the

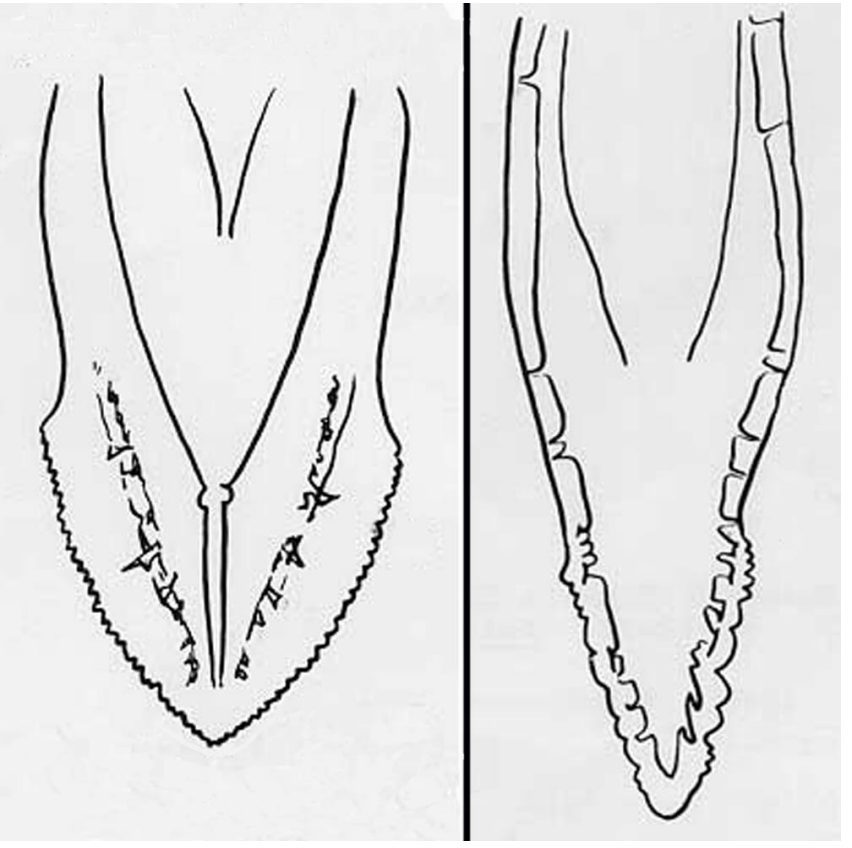

Figure 3. Comparison of the ovipositors of the schoepfia fruit fly, Anastrepha interrupta Stone (left), and the Caribbean fruit fly, Anastrepha suspensa (Loew) (right). Credits: Division of Plant Industry

$\mathrm{V}$ band is distinctly to narrowly connected with the S band on the anterior portion of the wing.

A. interrupta is closely related to A. spatulata Stone, which has been recorded from the Rio Grande Valley in Texas, Tamaulipas and Baja California in Mexico, and in Panama, but the difference in the wing pattern is so constant that there is little difficulty in distinguishing the two. Furthermore, the two species occupy widely separated ranges, having no endemic species in common.

\section{Larval Description}

Larva white; typical fruit fly shape (cylindrical-maggot shape, elongate, anterior end narrowed and somewhat curved ventrally, with anterior mouth hooks, ventral fusiform areas, and flattened caudal end); last instar larvae range in length from 7.5-9.4 mm; venter with fusiform areas on segments 2-10; anterior buccal carinae usually 14-19 in number; anterior spiracles nearly straight in lateral view but with ends somewhat curved, and with tubules averaging 10- 12 in number.

Cephalo-pharyngeal skeleton with large pointed convex mouth hook each side, with rounded dorsal lobe, and each hook about 2.5X hypostome length; 


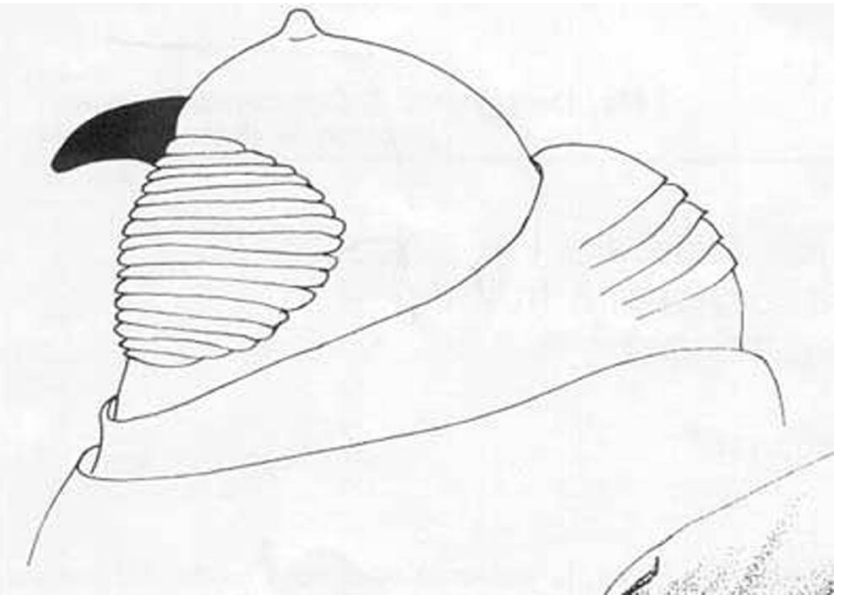

Figure 4. Larval head and buccal carinae of the schoepfia fruit fly, Anastrepha interrupta Stone. Credits: Division of Plant Industry

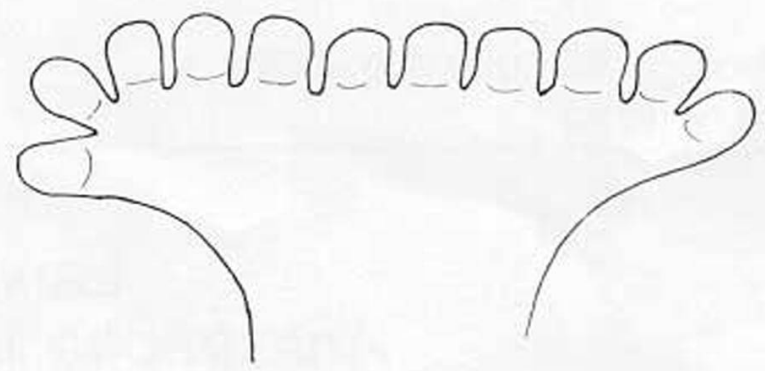

Figure 5. Larval anterior spiracles of the schoepfia fruit fly, Anastrepha interrupta Stone. Credits: Division of Plant Industry

hypostomium with extended elongate subhypostomium; posthypostomial plates curved to dorsal bridge, fused with prominent sclerotized rays of central dorsal wing plate; parastomium broadly elongate; dorsal wing plate with several prominent rays and small posterior ray split; dorsal bridge relatively evenly sclerotized; a prominent hood on pharyngeal plate.

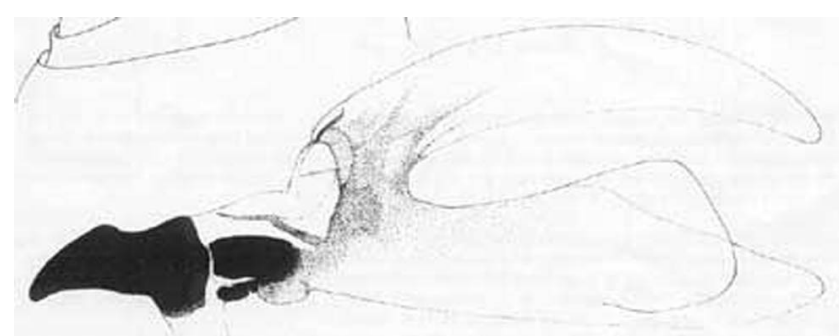

Figure 6. Larval cephalo-pharyngeal skeleton (left side) of the schoepfia fruit fly, Anastrepha interrupta Stone. Credits: Division of Plant Industry
Caudal end with paired dorsal papillules (D1 and D2) angled about 45 degrees from each spiracular plate; intermediate papillules 4 in number, with I1-2 in a nearly equidistant triangle with I4, and I3 distant dorso-laterally; L1 on dorso-lateral edge of caudal end; V1 about equidistant from I4 and anal lobes; posterior spiracles as 3 elongated peritremes (length $=4 \mathrm{X}$ width) on each spiracular-plate, with dorsal 2 peritremes angled to center from dorsal direction and remaining peritreme angled from venter; interspiracular processes (hairs) relatively few in number, at 4 sites on each plate, and tips sometimes bifurcate to trifurcate; anal lobes entire.

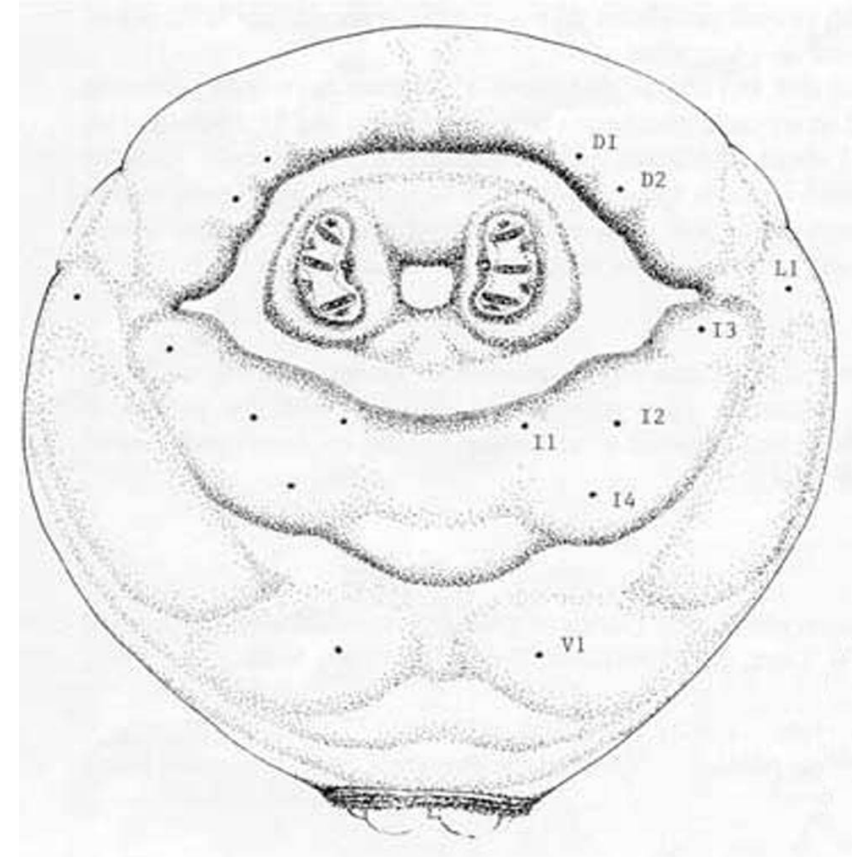

Figure 7. Caudal end of the last instar larva of the schoepfia fruit fly, Anastrepha interrupta Stone. Credits: Division of Plant Industry

The schoepfia fruit fly larva is particularly distinctive in relation to known Anastrepha larvae by the prominent depression of the entire caudal spiracular plate arrangement, together with the pattern of papillules, particularly the four intermediate pairs; This can be compared to an earlier circular on the Mexican fruit fly, Anastrepha ludens (Loew), and the Caribbean fruit fly, Anastrepha suspensa (Loew) (Heppner 1984). 


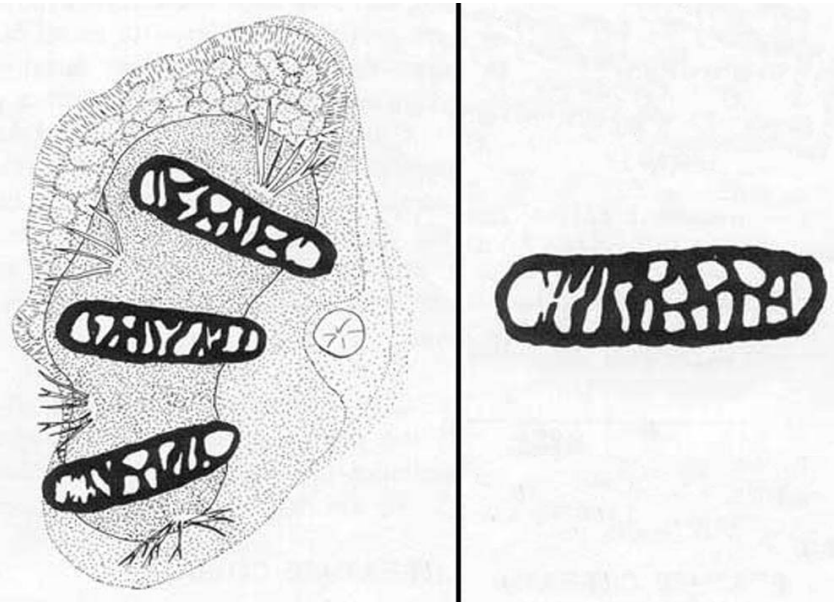

Figure 8. Posterior spiracles (left side) of the schoepfia fruit fly, Anastrepha interrupta Stone, with details of one peritreme. Credits: Division of Plant Industry

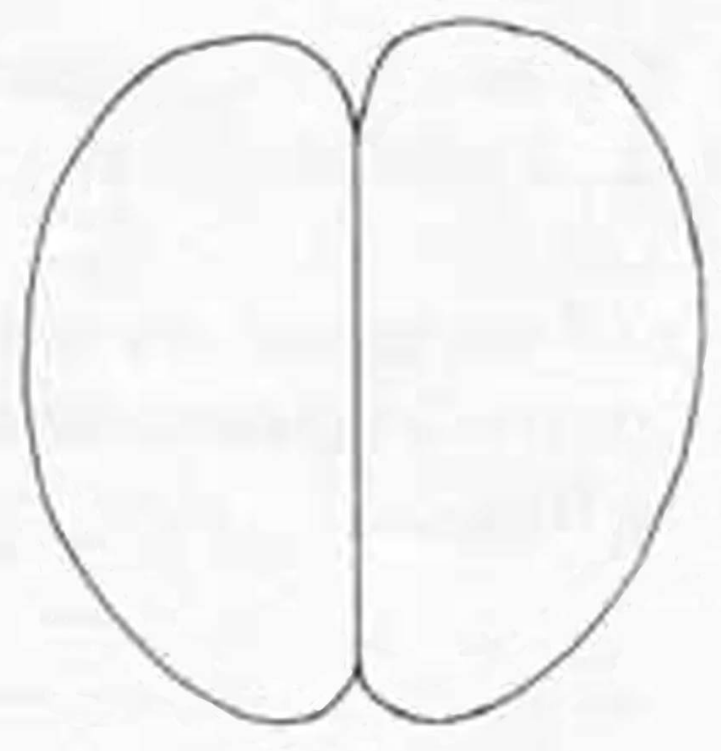

Figure 9. Larval anal lobes of the schoepfia fruit fly, Anastrepha interrupta Stone. Credits: Division of Plant Industry

\section{Selected References}

Heppner JB. 1984. Larvae of fruit flies I. Anastrepha ludens (Mexican fruit fly) and Anastrepha suspensa (Caribbean fruit fly) (Diptera: Tephritidae). Florida Department of Agriculture and Consumer Services, Division of Plant Industry Entomology Circular 260: 1-4.

State Plant Board of Florida Eleventh Biennial Report for the period July 1, 1934-June 30, 1936. Jan. 1937. p. 19-20. Anastrepha, n. sp. "E" Brown.
Stone A. 1942. The fruitflies of the genus Anastrepha. U.S. Department of Agriculture Miscellaneous Publication 439: 1-112, 23 pl.

Weems Jr HV. July 1965. Anastrepha suspensa (Loew) (Diptera: Tephritidae). Florida Department of Agriculture and Consumer Services, Division of Plant Industry Entomology Circular 38.

Weems Jr HV. 1967. Anastrepha interrupta Stone (Diptera: Tephritidae). Florida Department of Agriculture and Consumer Services, Division of Plant Industry Entomology Circular 61: 1-2. 